\title{
Avaliação Da Gestão De Instituição De Educação Superior: Uma Discussão Sobre Os Métodos
}

\section{Evaluation of Higher Education Institution Management: A Discussion on Methods}

DOI: $10.54019 /$ sesv3n1-011

Recebimento dos originais: 05/07/2021

Aceitação para publicação: 20/08/2021

\section{Rogério Da Silva Nunes}

Universidade Federal de Santa Catarina

E-mail: rognunes@msn.com

\section{Marcelo Dib Basílio}

Centro Universitário Carlos Drumond de Andrade

E-mail: mdbasilio@hotmail.com

\section{RESUMO}

O artigo apresenta uma discussão sobre a avaliação da gestão de instituições de educação superior, com o objetivo de contextualizar a produção vinculada a projetos de pesquisa direcionados a tal finalidade no âmbito do Programa de PósGraduação em Administração Universitária da Universidade Federal de Santa Catarina (PPGAU-UFSC). Inicialmente, apresenta uma síntese sobre os modelos teóricos que podem ser utilizados na avaliação estratégica e operacional de organizações. Os resultados apresentam a produção de dissertações e publicações ocorridas no período 2014-2020 por participantes dos projetos. No período analisado, ocorreram oito (8) dissertações concluídas, quatro (4) publicações em revista acadêmicas, quatro (4) capítulos de livros e vinte e três (23) publicações em eventos nacionais e internacionais no âmbito dos projetos de avaliação da gestão das instituições de educação superior registrados no programa.

Palavras chave: Avaliação; gestão de universidades; métodos de avaliação.

\section{ABSTRACT}

The article presents a discussion about the evaluation of the management of higher education institutions, with the objective of contextualizing the production linked to research projects directed to this purpose in the scope of the Graduate Program in University Administration at the Federal University of Santa Catarina (PPGAU-UFSC). Initially, it presents a synthesis of the theoretical models that can be used in the strategic and operational evaluation of organizations. The results present the production of dissertations and publications that occurred in the period 2014-2020 by project participants. In the period analyzed, there were eight (8) 
completed dissertations, four (4) publications in academic journals, four (4) book chapters and twenty-three (23) publications in national and international events within the scope of the projects on evaluation of the management of higher education institutions registered in the program.

Keywords: Evaluation; management of universities; evaluation methods.

\section{INTRODUÇÃO}

Segundo Schilickman e Melo (2012) não há uma definição clara do marco teórico dos estudos em Administração Universitária, mas é possível relacioná-lo à fundação da Association Internationale des Universités (IAU) uma associação mundial ligada à UNESCO fundada no ano de 1950, em Nice na França e com sede em Paris.

A partir da constituição da IAU, surgem muitos trabalhos. Em 1966, um grupo de trabalho formado por seis dirigentes de universidades reuniu-se em Paris para discutir os sistemas de Administração Universitária de seis países ou regiões do mundo. O resultado da discussão desse grupo de trabalho deu origem ao Caderno no 08 da IAU, intitulado L'Administration des Universites, publicado em 1967.

No mesmo ano da publicação do Caderno no 8 da IAU, iniciava-se no Brasil um ciclo de estudos sobre Administração Universitária envolvendo diretores e técnicos em administração universitária das universidades brasileiras realizados na Universidade Federal de Santa Catarina (UFSC). O término destes estudos culminou com o Seminário Internacional de Administração Universitária - SIAU, realizado em 1971.

Em 1973, a Universidade Autônoma de Guadalajara em parceria com a Organização dos Estados Americanos (OEA) realizou no México um Seminário sobre Administração Universitária cuja discussão resultou na publicação em cinco volumes: (1) Teoria sobre Administração Universitária e Administração Acadêmica; (2) Financiamento da Universidade; (3) Organização Departamental; (4) Sistema Integrado de Planejamento e Controle; e (5) Administração da Planta Física.

A partir de então vários eventos para tratar do assunto ocorreram. Entre os quais, Schlickmann e Melo (2012) destacam como ponto de partida a publicação do livro Administração Acadêmica Universitária: a teoria, o método, em 1977, e o 
Seminário Internacional de Administração Universitária organizado pela Universidade Nacional Autônoma do México em 1979.

Um dos temas relevantes na Administração Universitária é a avaliação, que se trata igualmente de fenômeno recente, com exceção dos Estados Unidos, onde Durhan (1992) afirma que há muito tempo são feitas avaliações regulares por órgãos não governamentais. Para Schwartzman (1990). Embora tenha uma tradição mais antiga na América do Norte, a temática da avaliação do ensino superior ainda é algo recente no contexto latino americano e europeu. Na Europa, o autor cita o surgimento do artigo Evaluate State, que aborda uma modalidade de governo que procura substituir os tipos mais tradicionais de controle burocrático ou planejamento de atividades a priori por mecanismos de avaliação a posteriori.

Os autores convergem nos exemplos europeus ao citar as experiências da França e Holanda, países que consideram o estado avaliador como uma forma de descentralização que procura livrar as universidades do controle formal e burocrático do governo federal, fazendo com que estas deixem de ter que atingir e ampliar os padrões de desempenho estabelecidos pela sociedade. (DURHAN, 1992)

House (1992); Allen (1996) e Durham (1992; 2006) alertam que a avaliação não pode ser utilizada como um instrumento de centralização e pressão unilateral do Estado e nem como um elemento para substituir as pressões de mercado que provoca uma pressão generalizada no sentido de promover a adaptação das instituições.

Afonso (2000) destaca que a avaliação é um pré-requisito para que seja possível o desenvolvimento de mecanismos de controle e responsabilização desejados pelo Estado, haja vista que, sem objetivos claros e previamente definidos, não é possível criar indicadores e medir as performances dos sistemas. Nessa linha, Schwartzman (1990) e Durham (1992) destacam que sem a avaliação, não há nenhum mecanismo que estabeleça o desenvolvimento das instituições como um parâmetro para a distribuição de recursos, pois é ela que viabiliza a implantação de uma política menos personalista. Daí a necessidade de que o processo de avaliação seja transparente, utilize-se de critérios legítimos para a definição e alcance de padrões de qualidade aceitáveis. 
Assim, o artigo tem como objetivo apresentar uma discussão os diferentes métodos utilizados para avaliar a gestão das instituições de educação superior. Tal discussão está inserida em projetos de pesquisa vinculados ao Programa de Pós-Graduação em Administração e o artigo apresenta os resultados de tais projetos.

\section{AVALIAÇÃO DE INSTITUIÇÕES DE EDUCAÇÃO DE EDUCAÇÃO SUPERIOR}

As IES têm se adaptado às mudanças propostas pelo Ministério da Educação (MEC), orientando-se por um conjunto de diretrizes e políticas. Diante da dimensão que o ensino superior brasileiro atingiu no início do século XXI, houve uma preocupação com a qualidade dos serviços de educação e, com isso, a avaliação fundamentada no SINAES passou a ser um instrumento valioso para garantir a qualidade do ensino superior.

De acordo com Correa et al. (2008), o SINAES foi criado com a finalidade de realizar uma avaliação da educação superior de caráter diagnóstico, formativo e regulatório, buscando sempre o avanço constante da qualidade da educação superior, o aumento contínuo de sua eficácia institucional, efetividade acadêmica e social e a promoção do aprofundamento dos compromissos e responsabilidades sociais das IES.

A Educação Superior se consolida em um momento onde ocorre pressão para atender demandas por novas tecnologias, eficiência e eficácia organizacional e, em especial, na geração de conhecimento e formação de recursos humanos qualificados. Neste sentido, Polidori et al (2006), destacam a importância da construção e a existência do SINAES, para que as IES desenvolvam a sua gestão utilizando-se das informações advindas deste processo amplo de avaliação, e que, em última instância, os resultados sirvam como mecanismos para enriquecer o planejamento das IES e subsidiar políticas internas de desenvolvimento de oferta de um ensino superior de qualidade e também de políticas públicas educativas.

Tem sido perceptível a adoção do planejamento estratégico, com destaque para aplicação de forma mais consistente nas organizações públicas, que a partir das reformas dos órgãos do Estado orientadas sob a abordagem do modelo 
gerencial, passou a enfatizar a eficiência, eficácia e efetividade governamental (MARCELINO, MATIAS-PEREIRA, BERBERT, 2008).

A utilização de metodologia e terminologia de planejamento estratégico nos coloca o desafio de discutir o alinhamento das ações da gestão acadêmica, fixando a crescente utilização da Tecnologia da Informação e as Estratégias Corporativas. Nesse sentido, faz necessário desenvolver indicadores que permitam avaliar a gestão.

Para Callado et al. (2008) é necessário observar a existência organizacional sob a perspectiva gerencial atribuída à elaboração, implantação e monitoramento através de indicadores de desempenho como suporte referencial para o processo decisório institucional.

Rodrigues at al. (2003) afirmam que o sistema de indicadores deveria ser planejado visando avaliar os aspectos relevantes para a gestão, garantindo coerência e adequação aos interesses institucionais, evitando o erro da gestão sem indicadores ou em excesso. Reforçando, Fischmann e Zilber (2000, p.1) afirmam que os indicadores de desempenho são "instrumentos capazes de auxiliar na definição do planejamento estratégico e na consequente determinação das estratégias" e "permitem verificar a propriedade com que as decisões foram tomadas e, eventualmente, corrigir e readequar o processo vigente de gestão".

Para Warrak et al. (2001), os indicadores de desempenho (i) permitem comparar os resultados com padrões previamente estabelecidos; (ii) avaliam quantitativamente o nível de desempenho (qualitativo ou quantitativo) de resultados desejados; e (iii) oferecem a oportunidade de serem tratados como alvo permanente desafio. Ainda com relação a indicadores de gestão, Rodrigues et al. (2003) apresentaram os seguintes indicadores de avaliação das universidades:

- Políticas institucionais - porcentagem de atingimento das metas propostas;

- Estrutura organizacional - avaliação do quadro administrativo (quantitativa e qualitativa) e do clima organizacional;

- Infraestrutura de apoio - área construída (m2/aluno), área em construção (m2/aluno), área de estacionamento (m2/aluno), área de lazer (m2/aluno), avaliação qualitativa de prédios e equipamentos

- Capacitação de docentes e funcionários - porcentagem de docentes e funcionários com titulação de graduação, especialista, mestre e doutor;

- Qualificação de docentes e funcionários - titulação (graduados, especialistas, mestres e doutores), dedicação integral, experiência profissional e resultados da avaliação interna de desempenho de docentes e funcionários; 
- Volume de recursos financeiros - resultado do balanço patrimonial do exercício anterior, investimentos ( $\mathrm{R} \$$ /aluno) e inadimplência (\%);

- Distribuição dos recursos financeiros - distribuição por dimensão (\% para graduação, pós, pesquisa e extensão) e distribuição por área de conhecimento;

- Imagem da instituição junto à comunidade - porcentagem dos níveis de satisfação da comunidade, empresas e público interno, resultados das avaliações externas.

\section{MÉTODOS DE AVALIAÇÃO DA GESTÃO}

No entanto, há outras proposições de indicadores de avaliação da gestão de organizações que podem ser aplicadas, ou adaptadas, às instituições de educação superior.

\subsection{Método Tableau de Bord}

Pioneiro na mensuração do desempenho organizacional, este modelo foi criado na França, no início do século $X X$, quando engenheiros de processos procuravam formas de melhorar a produção. Os criadores aplicaram o mesmo princípio na administração da organização, proporcionando à alta administração uma gama de indicadores que apontaria o desempenho dos negócios.

De forma análoga a um painel de instrumentos, estes indicadores de desempenho são formulados em termos de quantidades (nome, porcentagens), qualidade (valor relativo), montante financeiro (custos, receitas) e tempo (frequência, prazo).

Um ponto importante da metodologia é a existência de um padrão universal de Tableau de Bord, sendo, portanto, desenvolvido para cada organização e atendendo às suas peculiaridades. Voyeur (1994) apud Rosa (2003) divide o processo de desenvolvimento do Tableau de Bord nas seguintes etapas:

1. Determinação dos indicadores necessários e disponíveis e escolha dos indicadores pertinentes a conservar;

2. Descrição do setor alvo e precisão dos objetos de gestão, dos objetivos, das preocupações de gestão;

3. Preparação organizacional do projeto: contexto, pertinência, envergadura, escolha do setor alvo e da área piloto, recursos e responsabilidades;

4. Precisão dos indicadores e seus parâmetros: definição, medida efetuada, ventilação, limites, desvios e tendências, forma visual;

5. Desenho do Tableau de Bord: agenciamento dos indicadores, apresentação da visão e dos relatórios ventilados e sinópticos, personalização;

6. Informatização: aquisição, desenvolvimento do sistema informatizado de produção do Tableau de Bord e adaptação dos sistemas de informações existentes;

Hourneaux (2005) destaca que o Tableau de Bord funciona como um método para responder as seguintes perguntas:

- Quem? Deve representar os responsáveis dentro da estrutura administrativa; como se dá a delegação das tarefas; e como funcionam os sistemas de comunicação e informação;

- O quê? Quais as informações que interessam em cada função e a uma determinada responsabilidade na organização;

- Como? Assinalar tendências ou acontecimentos incomuns e orientar em direção a análise mais aprofundada; 
- Quando? Deve ter a frequência necessária para comunicar uma mesma informação em um ou mais níveis hierárquicos, ou em um mesmo nível hierárquico, variando a natureza das informações.

Bord seriam:

O autor afirma ainda que as principais vantagens do uso do Tableau de

- Prover a cada gerente uma visão geral e concisa do desempenho de sua unidade para guiar a tomada de decisão;

- Informar o próximo nível sobre o desempenho de cada unidade;

- Forçar cada unidade a se posicionar com relação ao contexto da estratégia global da empresa, com relação às responsabilidades das demais unidades e identificar os fatores críticos de sucesso e indicadores chave de desempenho;

- Contribuir para estruturar a agenda e dirigir o foco e as discussões administrativas.

Segundo DeBusk et al (2003) a grande desvantagem do método do Tableau de Bord é a ênfase nos tradicionais indicadores financeiros, colocando os não-financeiros em segundo plano. Além disto, destaca as principais críticas ao uso do Tableau de Bord:

- Não parte de uma estratégia estabelecida a priori;

- Ênfase nos indicadores financeiros, deixando em segundo plano os nãofinanceiros;

- A extensão do método, quando colocado em prática;

- As metas, que são comparadas somente internamente e não com outras empresas;

- A priorização dos objetivos de cada área ao invés da estratégia global.

\subsection{Método de Martindell}

O então presidente do American Institute of Management, Jackson Martindell, descreveu em 1950 uma ferramenta que permitiria a realização de uma análise completa das organizações. Para Martindell, um método de avaliação deve atender aos seguintes critérios:

- Flexibilidade: aplicação estendida a diversos tipos de administração e a vários campos do conhecimento;

- Inteligibilidade: entendimento quanto a questões que serão abordadas e retratarão a realidade da organização;

- Comparabilidade: possibilidade de comparação entre organizações;

- Mensurabilidade: as medidas refletem a qualidade da administração;

- Enfoque sistêmico: consideram-se as várias inter-relações e a interdependência que ocorrem dentro das organizações;

Buchele (1971, p. 142), considera que, do ponto de vista da mensuração numérica, "talvez o melhor sistema de avaliação publicado seja aquele 
desenvolvido por Jackson Martindell'.

O método consta de 10.000 pontos para a avaliação de desempenho, sendo que esta seria a pontuação máxima que uma organização pode atingir (MARTINDELL, 1950). Esses pontos seriam atribuídos a dez variáveis distintas, listadas no Quadro 1, que permitiriam a mensuração e a avaliação da organização nestes dez quesitos, obtendo-se, assim, uma pontuação global da organização.

Quadro 1: Variáveis para mensuração e a avaliação da organização
\begin{tabular}{|l|c|}
\hline \multicolumn{1}{|c|}{ VARIÁVEIS } & MÉDIA MÁXIMA \\
\hline Função econômica & 1.000 \\
\hline Estrutura organizacional & 500 \\
\hline Saúde dos lucros & 600 \\
\hline Serviços para os acionistas & 700 \\
\hline $\begin{array}{l}\text { Pesquisa } \\
\text { desenvolvimento }\end{array}$ & 800 \\
\hline Análise da diretoria & 800 \\
\hline Política fiscal & 1.000 \\
\hline Eficiência da produção & 1.100 \\
\hline Vigor das vendas & 1.300 \\
\hline Avaliação de executivos & 2.200 \\
\hline \hline Total & $\mathbf{1 0 . 0 0 0}$ \\
\hline
\end{tabular}

Fonte: Martindell (1950)

O pioneirismo do método, sua ampla aplicabilidade e o enfoque quantitativo que apresenta são pontos de destaque (ROBBINS, 1978; CORRÊA, 1986). Porém, Corrêa (1986) faz ressalvas ao método quanto à subjetividade inerente ao processo de ponderação das variáveis componentes da avaliação.

\subsection{Método de Buchele}

Em 1970, Robert Buchele, da Universidade do Havaí, publicou um manual para avaliação de empresas, como um todo ou alguns aspectos (BUCHELE, 1971). O autor divide o livro em duas partes: (1) avaliação para pequenas empresas e as possíveis crises que Ihes são próprias e (2) avaliação para médias e grandes empresas, em que expõe o método da avaliação direta, que visa examinar a qualidade da administração, através do estudo dos processos administrativos: planejamento, controle, organização, assessoria e direção (BUCHELE, 1971, p. 142). Para o autor há 3 (três) possíveis tipos de avaliação nas organizações, como se observa no Quadro 2: 


\section{Quadro 2: Tipos de avaliação nas organizações}

\begin{tabular}{|c|l|l|}
\hline $\begin{array}{c}\text { Tipo de } \\
\text { Avaliação }\end{array}$ & \multicolumn{1}{|c|}{ Vantagens } & \multicolumn{1}{|c|}{ Desvantagens } \\
\hline $\begin{array}{c}\text { Análise } \\
\text { Financeira }\end{array}$ & $\begin{array}{l}\text { Focaliza claramente índices } \\
\text { vitais para a organização; É } \\
\text { facilmente aplicável; } \\
\text { Fornece informações que } \\
\text { mais interessam aos bancos. }\end{array}$ & $\begin{array}{l}\text { Contempla o passado, e não o futuro; } \\
\text { Lentidão para apuração; Revela mais os } \\
\text { sintomas que as causas dos problemas; } \\
\text { Instabilidade das informações. }\end{array}$ \\
\hline $\begin{array}{c}\text { Análise pelos } \\
\text { Departamentos } \\
\text { Principais }\end{array}$ & $\begin{array}{l}\text { Ajuda o avaliador a se } \\
\text { certificar se não esqueceu de } \\
\text { nada importante; Apresenta } \\
\text { ideias que podem ajudar na } \\
\text { melhoria das operações }\end{array}$ & $\begin{array}{l}\text { Não integra os departamentos; A } \\
\text { dificuldade de aplicação, devido à } \\
\text { especificidade de estrutura de cada } \\
\text { organização; Ênfase na situação atual, } \\
\text { sem considerar o futuro }\end{array}$ \\
\hline \hline $\begin{array}{c}\text { Análise dos } \\
\text { Processos }\end{array}$ & $\begin{array}{l}\text { Verifica o desempenho de } \\
\text { cada um dos processos: } \\
\text { planejamento, controle, }\end{array}$ & $\begin{array}{l}\text { Dificuldade de separação clara entre os } \\
\text { diferentes processos; Dificuldade de } \\
\text { integração da organização como um } \\
\text { todo }\end{array}$ \\
\hline $\begin{array}{c}\text { Administrativos } \\
\text { torganização, assessoria e } \\
\text { liderança }\end{array}$ & \\
\hline
\end{tabular}

Fonte: Buchele (1971)

O autor considera a necessidade de se avaliar analiticamente e mensurar seu desempenho quantitativamente e há dois focos que devem ser explorados pelos administradores: (1) "a habilidade da empresa em aperfeiçoar incessantemente o desempenho de suas operações atuais" e (2) habilidade em aperfeiçoar a situação futura da empresa, em termos de políticas e programas, análise das ameaças e oportunidades, capacidade de inovação, habilidade para desenvolver novos produtos e serviços e, finalmente, a possibilidade de atração e desenvolvimento por parte dos administradores (BUCHELE, 1971, p. 181).

Assim, a avaliação direta ocorre através da análise dos processos administrativos:

1) Análise da força competitiva: passado, presente e futuro da organização, em que são avaliados: planos e objetivos; produtos ou serviços; e capacidade de desenvolvimento de produtos ou serviços.

2) Análise dos departamentos principais, em que são avaliados: extensão do desenvolvimento dos departamentos; registro do desempenho; e características da administração.

3) Análise financeira, em que são avaliados: tendências da situação geral; posição atual; aproveitamento das informações; estrutura do capital; e valor da 
empresa.

4) Análise da administração de cúpula, em que são avaliados: identificação e registro da administração de cúpula; tendências da capacidade da administração de cúpula; e sucessão administrativa.

Para Corrêa (1986), o método de Buchele não é integrado e não são claras as maneiras de implementá-lo. O próprio autor afirma que, em função de uma simplificação, só estão consideradas algumas das variáveis organizacionais, abrindo a possibilidade de algum outro fator relevante ser deixado de lado em um caso específico (BUCHELE, 1971).

\subsection{Métodos Administração por Objetivos e Áreas-chave de Resultado}

O surgimento da Administração por Objetivos ocorreu nos anos 50, em um momento de crise das empresas norte-americanas. Para Lodi (1976), a pressão econômica da época gerou uma administração por pressão (management by pressure) que coincidiu com o aperfeiçoamento dos controles administrativos. A pressão exercida sobre os gerentes não estava provando ser a melhor maneira de obter resultados e foi nesse período que apareceu a Administração por Objetivos (APO)

Greenwood (1981) argumenta que precursores de Drucker escreveram sobre a necessidade de traçar objetivos como base para a administração, mas não usaram o termo APO, o autor destaca Henri Fayol (1916), James O. Mckinsey (1922), Chester I. Barnard (1938), Mary Parker Follett (1941), Ralph C. Davis (1937, 1940, 1951), Harry Hopf (1973).

APO é um método em que os objetivos estratégicos são definidos em conjunto pela alta administração e demais funcionários; as responsabilidades são especificadas individualmente em função do que a empresa pretende alcançar no futuro, considerando pontos fortes e fracos e as circunstâncias existentes no mercado. Com isso, a organização estabelece padrões de desempenho sob os quais os gerentes serão avaliados. Analisando o resultado final, o desempenho do gerente pode ser objetivamente avaliado e os resultados alcançados com as metas estabelecidas.

Na visão de Lupoli Jr. e Ângelo (2002), deve-se ressaltar a ideia de utilização dos objetivos como fator de motivação. Autores adeptos da psicologia do trabalho, ressaltam a importância da vinculação de objetivos desafiadores com a melhoria de desempenho, onde as relações interpessoais funcionam como elemento fundamental para a construção de uma linguagem, o tanto quanto possível, comum nas organizações. 
Drucker (1968) afirma que é um erro estabelecer a busca do lucro como o objetivo principal da organização. Administrar implica equilibrar uma variedade de necessidades e finalidades em todos os setores que possam vir a afetar a sobrevivência organizacional e identificou 8 áreas-chave para os quais tinham de ser fixados objetivos: (1) rentabilidade; (2) posição no mercado; (3) produtividade; (4) recursos físicos e financeiros; (5) inovação; (6) desempenho e desenvolvimento de gerentes; (7) desempenho e atitude dos trabalhadores; e (8) responsabilidade pública.

\subsection{Modelo de Corrêa}

Em 1986, Corrêa propôs um método de avaliação que consiste nos seguintes pontos:

1) Descrição da empresa, seus objetivos e missões;

2) Definição dos módulos de desempenho (áreas da organização). O autor sugere considerar os seguintes módulos: (a) Econômico-financeiro (desempenho financeiro); (b) Operacional ( produtividade); (c) Recursos humanos (desempenho dos recursos humanos); (d) Satisfação dos usuários/clientes (o nível de satisfação); (e) Inovação tecnológica (grau de inovação gerada internamente); (f) Adaptação ao ambiente (capacidade da empresa de se adaptar ao ambiente presente e futuro); (g) Avaliação técnica (qualidade dos equipamentos, máquinas e tecnologia); (h) Clima organizacional (qualidade da interação entre as pessoas e setores e as consequências das interações); (i) Benefícios sociais (benefícios sociais gerados); e (j) Potencialidade gerencial (capacidade e a potencialidade dos gerentes da organização0;

3) Definição dos indicadores de cada módulo: identificação, seleção, hierarquização e metodologia de levantamento de dados.

4) Definição dos padrões de desempenho, definidos por realização de benchmarking interno e externo, além de considerar as contingências próprias da organização e ambientais;

5) Avaliação e feedback: consiste na identificação do desempenho de cada fator, sua comparação com o padrão estabelecido e, possivelmente, revisão dos indicadores e sua hierarquização; 
6) Verificação das causas do desempenho: estabelecimento de relações das causas e efeitos para as variáveis de desempenho e análise das causas para possíveis correções e melhorias (CORRÊA, 1986, p. 197-208).

Essa definição está apresentada na Figura 1.

Figura 1: Método de avaliação

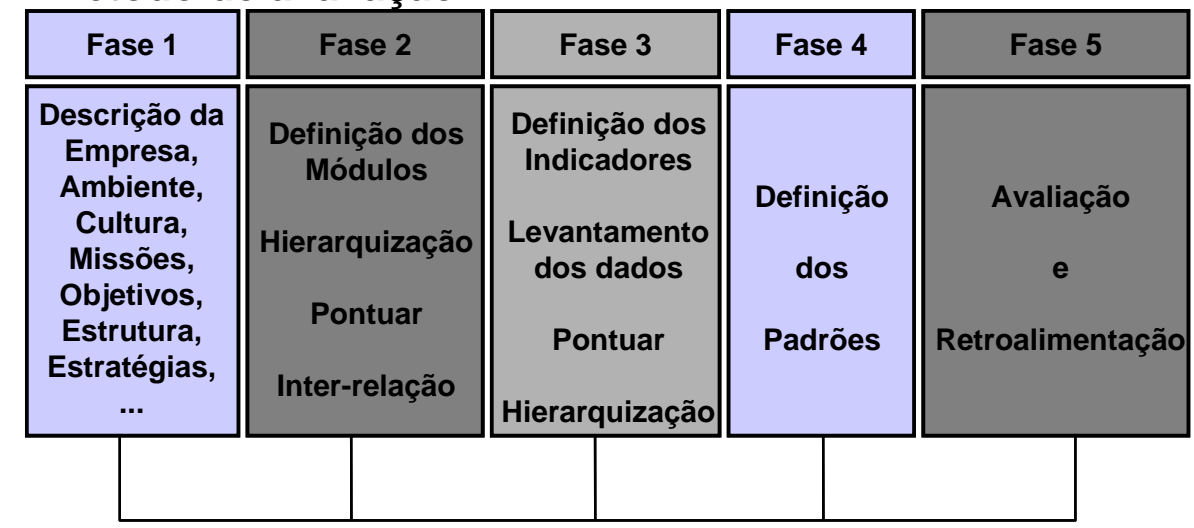

Fonte: Correa (1984)

O autor faz ressalvas quanto aos resultados obtidos pela mensuração e avaliação do desempenho, devido a quatro fatores restritivos: (a) bloqueio por parte dos funcionários, (b) bloqueio decorrentes de características gerenciais, (c) fatores relativos ao ambiente político-social da empresa e (d) limitações metodológicas (CORRÊA apud FARIAS NETTO, 1994). Destes, destaca-se a metodologia, que trata dos critérios estabelecidos internamente, não permitindo comparações com outras organizações.

Portanto, o número resultante levaria a um resultado sem significado real para a organização, em caso de falhas ou arbitrariedade na definição do processo (CORRÊA, 1986). Outros problemas quanto à eficácia dos métodos de avaliação poderiam ser causados por resistência dos membros da organização; ineficiência dos sistemas de informação; concentração das discussões sobre o assunto na alta administração e influência de variáveis externas (FARIAS NETTO, 1994; CORRÊA, 1986).

\subsection{Total Quality Management}

A escola da qualidade total gerou diversos métodos de mensuração de resultado. Destacando-se os prêmios Deming, Malcom Baldrige, Prêmio Europeu da Qualidade e Prêmio Nacional da Qualidade.

Segundo Ishikawa (1986) apud Houneaux (2005) o nome Deming é uma 
homenagem ao Dr. W. E. Deming, um dos maiores nomes na área da qualidade e cujo trabalho influenciou profundamente a indústria japonesa. O autor sintetiza esses conceitos em sete pontos:

- Melhoria da estrutura orgânica da empresa;

- Congregação dos esforços globais da empresa, através da participação de todos os funcionários e consolidação de uma estrutura que proporciona a cooperação;

- Confiança dos consumidores e dos usuários - consolidação do sistema de garantia da qualidade;

- Visar a melhor qualidade do mundo e desenvolver novos produtos com esse propósito;

- Assegurar o lucro e estruturar-se para superar a fase de crescimento estabilizado e de mudanças externas;

- Respeito à pessoa humana, sua preparação e educação, felicidade dos funcionários, criação de um ambiente salutar de trabalho e sua transposição para gerações futuras;

- Uso das técnicas de controle de qualidade.

Segundo o autor, há dez critérios básicos para a mensuração e a avaliação das empresas: (1) Políticas e objetivos; (2) Organização e sua operação; (3) Educação e sua disseminação; (4) Reunião e disseminação de informações e sua utilização; (5) Análise; (6) Padronização; (7) Controle; (8) Garantia de qualidade; (9) Efeitos; e (10) Planos futuros.

De forma análoga ao Prêmio Deming, os Estados Unidos criaram Prêmio Malcolm Baldrige em 1987, seguido da criação da Foundation for the Malcolm Baldrige National Quality Award em 1988, encarregada de promover e administrar a entrega do prêmio. Segundo Hourneaux, Corrêa e Maximiano (2006) este prêmio adota como metas do desempenho organizacional 3 métricas básicas: (1) entrega de valor com melhoria contínua aos clientes, contribuindo para o sucesso de mercado; (2) melhoria das competências e efetividade da organização; e (3) aprendizado organizacional e pessoal

O Prêmio Malcom Baldrige é dividido em sete categorias, que configuram os critérios desenhados para ajudar as organizações em uma perspectiva de desempenho organizacional. As categorias são: (1) Liderança; (2) Planejamento 
estratégico; (3) Foco no cliente e no mercado; (4) Mensuração, análise e conhecimento administrativo; (5) Foco em recursos humanos; (6) Administração de processos; e (7) Resultados do negócio.

Em 1988, foi fundada a European Foundation for Quality Management (EFQM) resultado do esforço de quatorze empresas europeias. A EFQM possui um "modelo de excelência" para avaliação de desempenho e administra o Prêmio Europeu da Qualidade.

Figura 2: O modelo da EFQM

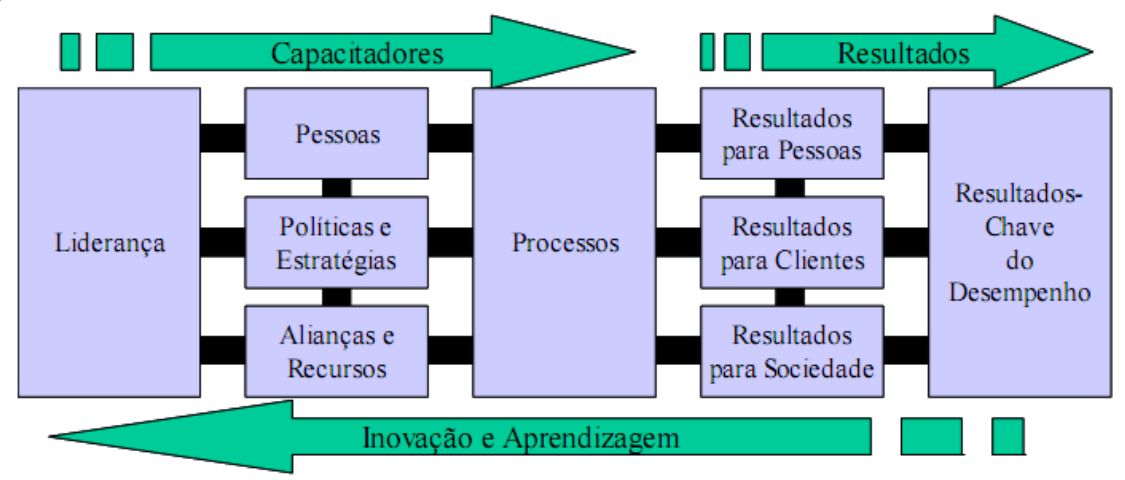

Fonte: Hourneaux, Corrêa e Maximiano (2006)

O "Modelo de Excelência da EFQM" é constituído por nove variáveis:

1. Liderança: aspectos envolvidos com a missão, a visão, os valores e a ética, que moldam a cultura da excelência; desenvolvem, implementam e melhoram a gestão da organização; interagem com clientes, parceiros e representantes da sociedade; reforçam a cultura da excelência; e identificam e patrocinam a mudança dentro da organização;

2.Política e Estratégia: devem privilegiar o foco nos stakeholders, suas necessidades e expectativas, atuais e futuras; focar nos indicadores de desempenho e nas atividades relacionadas à mensuração deste desempenho; e devem ser comunicadas e desdobradas através de uma rede de processoschave;

3.Pessoas: verificar-se são planejados, geridos e melhorados; se os conhecimentos e competências dos indivíduos são identificados, desenvolvidos e sustentados; se as pessoas são envolvidas e responsabilizadas; e as pessoas são reconhecidas, recompensadas e assistidas pela organização;

4. Parcerias e Recursos: deve haver um gerenciamento das parcerias externas; a gestão financeira é efetuada; gerenciamento das instalações, equipamentos 
e materiais; a tecnologia é gerenciada; e se há a gestão da informação e do conhecimento;

5.Processos: os processos são sistematicamente concebidos e geridos; são melhorados, através da inovação, satisfazendo e gerando valor para os stakeholders; os produtos e serviços são concebidos e desenvolvidos a partir das necessidades e expectativas dos clientes, com a adequada produção, entrega e assistência; as relações com os clientes são geridas e valorizadas;

6. Resultados se é medida a percepção dos clientes; e se funcionam como indicadores de desempenho da organização;

7.Resultados para as pessoas: medidas da percepção das pessoas; e se funcionam como indicadores de desempenho da organização;

8. Resultados para a sociedade: são medidas da percepção da sociedade; e se funcionam como indicadores de desempenho da organização;

9. Resultados-chave do desempenho: refletem e medem a política e a estratégia da organização; e funcionam como indicadores-chave do desempenho da organização.

O Prêmio Nacional de Qualidade (PNQ) foi inspirado no prêmio norte americano Malcom Baldrige, possuindo diversos critérios semelhantes. O prêmio brasileiro é administrado pela Fundação Nacional da Qualidade fundada em outubro de 1991 por 39 organizações, privadas e públicas.

Figura 3: O Modelo de Excelência do PNQ

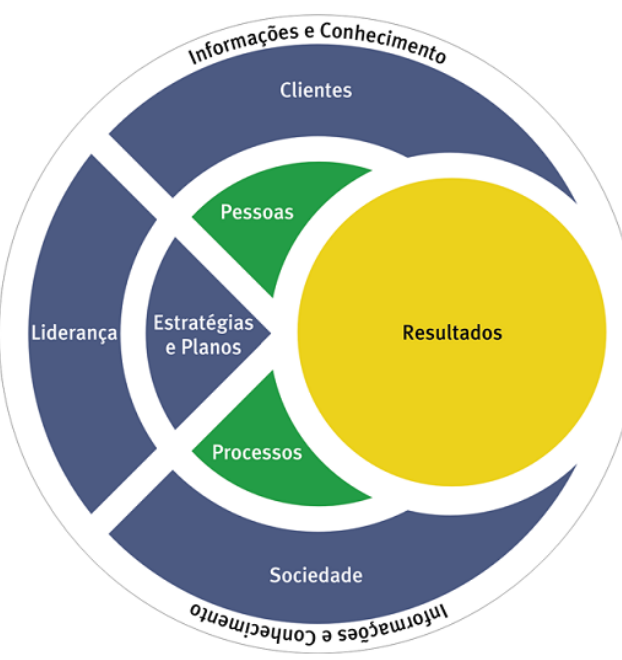

Fonte: PNQ (2007)

Conforme a Figura 3, o PNQ (2007) estabelece oito critérios de excelência 
referem-se a:

1. Liderança: examina o sistema de liderança da organização e o comprometimento pessoal dos membros da direção no estabelecimento, disseminação e atualização de valores e princípios.

2. Estratégias e Planos: examina o processo de formulação das estratégias, enfatizando a análise do setor de atuação, do macro ambiente e do modelo de negócio da organização. Também examina o processo de implementação das estratégias, incluindo a definição de indicadores, o desdobramento das metas e planos para todos os setores da organização.

3. Clientes: como a organização identifica, analisa e compreende as necessidades e expectativas dos clientes e dos mercados; divulga seus produtos, marcas e ações de melhoria.

4. Sociedade: examina como a organização contribui para o desenvolvimento econômico, social e ambiental de forma sustentável e como interage com a sociedade de forma ética e transparente.

5. Informações e Conhecimento: examina a gestão e a utilização das informações da organização e de informações comparativas pertinentes, bem como a gestão de seus ativos intangíveis.

6. Pessoas: examina como são proporcionadas as condições para o desenvolvimento e utilização plena do potencial das pessoas que compõem a força de trabalho.

7. Processos: examina como a organização identifica os processos de agregação de valor; e identifica, gerencia, analisa e melhora os processos principais do negócio e os processos de apoio.

8. Resultados: examina os resultados da organização, abrangendo os econômico-financeiros e os relativos aos clientes e mercados, sociedade, pessoas, processos principais do negócio e de apoio, assim como os relativos ao relacionamento com os fornecedores.

\subsection{Balanced Scorecard}

O balanced scorecard (BSC) teve origem com estudos elaborados por Robert S. Kaplan e David P. Norton centrados na necessidade de se encontrar novas formas de avaliar o desempenho organizacional. Seu objetivo central é definido pelos autores como "um conjunto de medidas que fornece à alta 
administração uma rápida, mas compreensiva visão dos negócios" (Kaplan e Norton, 2000).

Os autores propuseram um método simples de utilização dos indicadores de desempenho, que posteriormente deu origem ao livro em que Kaplan e Norton (1997) detalharam o conceito e apresentaram o BSC como um novo sistema de gestão estratégica.

Kaplan e Norton (2000) afirmam que o BSC capacita as organizações a focalizarem e alinharem suas equipes executivas, unidades de negócio, recursos humanos, recursos de tecnologia da informação e recursos financeiros à estratégia da organização. Assim os autores propõem cinco princípios, denominados "princípios da organização focalizada na estratégia":

- Traduzir a estratégia em termos operacionais: descrever e comunicar a todos os colaboradores da organização de forma a envolvê-los e alcançar os resultados;

- Alinhar a organização com a estratégia, envolvendo todos os colaboradores da organização;

- Transformar a estratégia em tarefa de todos: segundo os autores "As organizações focalizadas na estratégia exigem que todos os empregados compreendam a estratégia e conduzam suas tarefas cotidianas de modo a contribuir para o êxito da estratégia";

- Converter a estratégia em processo contínuo: a maioria das empresas concentra suas atividades em rever e comparar desempenhos, deixando de discutir as estratégias e até mesmo sua implementação;

- Mobilizar a mudança por meio da liderança executiva: estratégia demanda trabalho em equipe para a coordenação das mudanças.

\subsection{Sigma Sustainability}

Recentemente, houve um aumento na preocupação em mensurar a estratégia de forma global e sustentável, que pode ser definida como a capacidade de uma organização atingir suas metas, a partir da integração de oportunidades de crescimento social, ambiental e econômico.

Sustentabilidade propõe uma gestão sem prejudicar seres vivos e ambiente. Sustentabilidade "é aceitação da interdependência de diferentes aspectos da existência humana" (ANDREW; WEBER, 2007, p. 3). Resultado financeiro é importante e geram benefícios para os indivíduos e organizações, porém "outros valores humanos também são fundamentais, inclusive vida familiar, crescimento intelectual, expressão artística e desenvolvimento moral e espiritual' 
(ANDREW; WEBER, 2007, p. 3).

O Sigma Sustainability Scorecard. É um modelo adaptado do Balanced Scorecard (BSC) utilizando um modelo que conecta diferentes aspectos do desempenho organizacional. O Projeto Sigma - Sustainability Integrated Guidelines for Management (Diretrizes Integradas para Gestão com Sustentabilidade) - foi lançado oficialmente em 1999, pelo British Standards Institute (BSI). O modelo fortalece a compreensão da organização sobre sua própria operação e apoia a tomada de decisão. O Sigma Sustainability Scorecard faz duas adaptações principais no modelo do BSC: adota uma perspectiva de sustentabilidade, não apenas uma perspectiva financeira, e aborda a perspectiva dos stakeholders ao invés da visão apenas do cliente.

A perspectiva "partes interessadas externas" diz respeito a responsabilidade e stakeholder satisfeito. "Sustentabilidade" preocupa-se com sustentabilidade ecológica, direitos humanos e performance econômica. "Processos internos" apresenta como indicadores a ecoeficiência, produtividade e custo; e "Aprendizado e crescimento" diz respeito a inovação, aprendizado contínuo e capital intelectual.

Para a implantação do modelo é aconselhável definir valores, missão e visão da sustentabilidade e assegurar o apoio da liderança; identificar fatores críticos de sucesso; construir o modelo de mapa estratégico e identificar objetivos estratégicos, indicadores, metas e iniciativas estratégicas.

As orientações contidas no Projeto Sigma podem esclarecer dúvidas e transformar os desafios em oportunidades, para todas as empresas. Apontam também caminhos para a construção de um futuro sustentável, além de buscar as melhores práticas para empreender uma nova forma de trabalhar.

\subsection{Skandia Navigator}

O Navegador Skandia (Skandia Navigator) surgiu em 1995 na Suécia como resultado do grupo de pesquisa, liderado por Leif Edvinsson, sobre como identificar, mensurar, monitorar e gerenciar os componentes do Capital Intelectual (Cl). Para Edvinsson e Malone (1998) capital intelectual é composto por capital humano e capital estrutural, onde:

- Capital humano - conhecimento, experiência, poder de inovação e habilidade dos empregados de uma companhia para realizar as tarefas do dia-a-dia. Inclui 
também os valores, a cultura e a filosofia da empresa. O capital humano não pode ser de propriedade da empresa.

- Capital estrutural - formado por equipamentos de informática, softwares, bancos de dados, patentes, marcas registradas e todo o resto da capacidade organizacional que apoia a produtividade daqueles empregados (EDVINSSON E MALONE, 1998).

A Skandia atua no setor de seguros e serviços financeiros e foi a primeira organização a emitir um relatório público sobre capital intelectual denominado Visualizing Intellectual Capital.

Edvinsson e Malone (1998) afirmam que o Navegador Skandia, por meio da definição da visão e de sua estratégia empresarial, consegue maximizar os fatores críticos de sucesso. Esses fatores podem ser agrupados em cinco áreas de foco: Financeiro; Cliente; Processo; Renovação e desenvolvimento; e Humano.

Essas são as áreas nas quais uma empresa focaliza sua atenção e da interação entre os focos provém o valor de seu Capital Intelectual no âmbito de seu ambiente competitivo. Para cada área de foco são definidos indicadores de desempenho, por exemplo: receita resultante da atuação em novos negócios, participação de mercado (\%), duração média de relacionamento com o cliente e horas de treinamento (\%) conforme a Figura 5:

\section{Figura 5: Modelo Skandia}

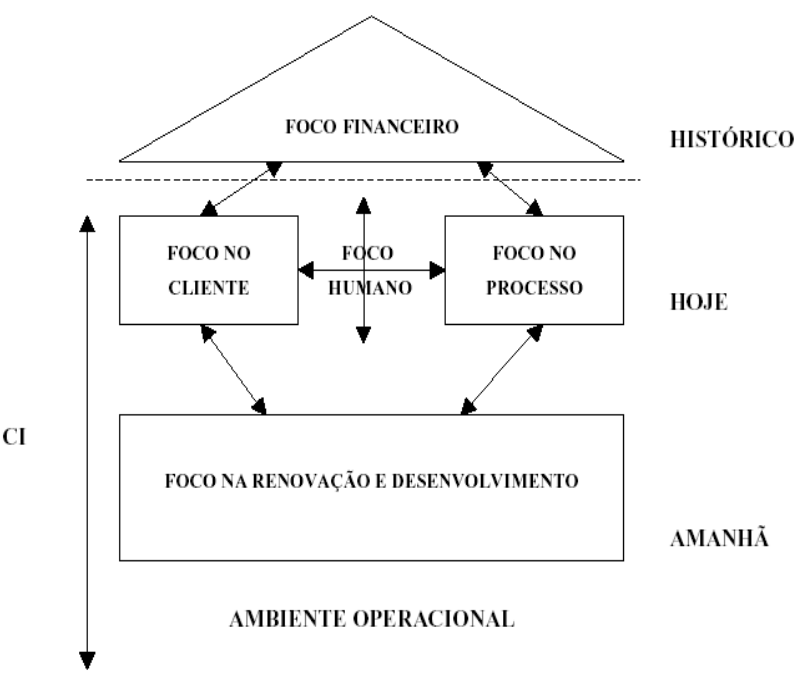

Fonte: Rezende (2003)

O Foco Financeiro é representado pelos demonstrativos financeiros. $\mathrm{Na}$ base do triângulo, encontram-se as notas explicativas originárias das operações 
da empresa relacionadas com clientes, pessoas e processos. O processo de procurar, traduzir e medir informações ocorre no centro do triângulo na capitalização financeira que permite avaliar e produzir indicadores relevantes para a organização. No topo do triângulo, estão as tabelas financeiras tradicionais representando a transformação dos ativos individuais de $\mathrm{Cl}$ em recursos financeiros. Após os dados financeiros serem processados por meio de indicadores, os dados formalizados são apresentados (EDVINSSON E MALONE, 1998).

O Foco no Cliente consiste em encontrar aqueles parâmetros que traduzem a nova realidade das relações entre organização e clientes. Edvinsson e Malone (1998) propõem:

1. Tipo do Cliente - identificação do perfil do cliente típico para o produto da empresa;

2. Duração do Cliente - qual a rotatividade dos clientes;

3. Tempo médio de lealdade do cliente;

4. Relação de produtos de consumo e clientes de várias gerações;

5. Papel do Cliente - participação do cliente no projeto, fabricação e entrega do produto;

6. Suporte - como a organização orienta programas, esquemas e tecnologias para assegurar a satisfação do cliente; e

7. Sucesso - níveis de sucesso relacionado com índice de compras, valor de compras, clientes novos.

O Foco no Processo trata do papel da tecnologia como instrumento de criação de valor para a organização, enfatizando a preocupação com os erros:

- Tecnologia Errada - escolher uma tecnologia antecipadamente pode ser uma vantagem, mas se for errada poderá ocasionar um custo irrecuperável;

- Fornecedor Errado - pode ser um diferencial devido à alta mortalidade das organizações.

- Aplicação Errada: adquirir novas tecnologias por modismos ou falta de compreensão das funções que a tecnologia deve desempenhar, pode influenciar a produtividade e ocasionar perda de capital.

O Foco de Renovação e Desenvolvimento estabelece o que a organização realiza em termos de planejamento atual visando à consolidação das 
metas e oportunidades do longo prazo. As organizações devem estar preparadas para mudanças e promover a renovação por meio de seis áreas de atuação:

- Clientes: mudanças na base de clientes; nível de suporte aos clientes; eficácia da comunicação entre a organização e sua base de clientes; etc.

- Atração de Mercado: investimento em inteligência de mercado; contribuição de novos mercados para a receita da organização; programas estruturados para rastrear novas invenções e novos concorrentes.

- Produtos e Serviços: produtos em desenvolvimento; contribuição histórica de um novo produto para a receita e lucros; investimento em novos produtos; número de patentes da organização.

- Parceiros Estratégicos: investimento no desenvolvimento de parcerias estratégicas; informações que não podem ser trocadas com os parceiros.

- Infraestrutura: expectativa de vida dos instrumentos; planejamento para aquisição de equipamentos; capacidade atual dos sistemas; relação entre investimento e lucro gerado pela aquisição de equipamentos;

- Empregados: nível de escolaridade dos funcionários; média de treinamento de cada empregado; investimento em programas de recrutamento de funcionários; etc. (EDVINSSON; MALONE, 1998).

O Foco Humano fica localizado no centro do Navegador Skandia e interage com os demais focos, constituindo a parte mais difícil do modelo de $\mathrm{Cl}$. Mensurar aspectos relacionados aos recursos humanos de uma organização não é tarefa fácil devido a dificuldade de coletar, medir e analisar o que se passa na mente dos funcionários com diferentes culturas e níveis sociais. Edvinsson e Malone (1998) sugerem um processo com início na concordância quanto a definições e metas, onde os parâmetros podem ser obtidos por meio de pesquisa sociológica, pesquisa de opinião, treinamento de habilidades.

\section{RESULTADOS}

Os projetos de pesquisa vinculados ao Programa de Pós-Graduação em Administração Universitária da Universidade Federal de Santa Catarina (PPGAUUFSC) têm desenvolvido uma série de pesquisas a respeito da avaliação da gestão de instituições de educação superior, o Quadro 3 apresenta a relação de dissertações ocorridas a partir de 2014: 
Quadro 3 - Dissertações - orientações concluídas a partir de 2014

\begin{tabular}{|c|c|c|}
\hline NOME & TíTULO & ANO \\
\hline $\begin{array}{c}\text { Amália Borges } \\
\text { Dário }\end{array}$ & $\begin{array}{c}\text { Avaliação do desempenho acadêmico e da evasão } \\
\text { entre discentes cotistas e não cotistas }\end{array}$ & 2017 \\
\hline $\begin{array}{c}\text { Carla Cristina da } \\
\text { Silveira Trilha }\end{array}$ & $\begin{array}{c}\text { Avaliação de desempenho dos almoxarifados da } \\
\text { Universidade do Estado de Santa Catarina }\end{array}$ & 2017 \\
\hline $\begin{array}{c}\text { Guilherme } \\
\text { Krause Alves }\end{array}$ & $\begin{array}{c}\text { Gestão de processos de compras: um estudo nas } \\
\text { universidades públicas catarinenses }\end{array}$ & 2017 \\
\hline $\begin{array}{c}\text { Maria das } \\
\text { Graças Martins }\end{array}$ & $\begin{array}{c}\text { Análise de processos: um estudo no restaurante } \\
\text { universitário da Universidade Federal de Santa } \\
\text { Catarina }\end{array}$ & 2017 \\
\hline $\begin{array}{c}\text { Tânia Regina } \\
\text { Tavares } \\
\text { Fernandes }\end{array}$ & $\begin{array}{c}\text { Avaliação da gestão de processos das } \\
\text { Coordenadorias de apoio administrativo dos Centros } \\
\text { de Ensino: estudo de caso }\end{array}$ & 2017 \\
\hline $\begin{array}{c}\text { Francine dos } \\
\text { Santos Corrêa } \\
\text { da Silva }\end{array}$ & $\begin{array}{c}\text { A inserção dos alunos dos cursos superiores em } \\
\text { tecnologia na pós-graduação 'lato sensu' }\end{array}$ & 2016 \\
\hline $\begin{array}{c}\text { Joice Regina da } \\
\text { Costa Santana } \\
\text { da Lapa }\end{array}$ & $\begin{array}{c}\text { Desafios e perspectivas na gestão de contratos de } \\
\text { serviços terceirizados de limpeza na UFSC }\end{array}$ & 2015 \\
\hline $\begin{array}{c}\text { Ana Paula } \\
\text { Guimarães }\end{array}$ & $\begin{array}{c}\text { Os parâmetros de avaliação do SINAES na } \\
\text { percepção dos estudantes do Curso de Graduação } \\
\text { em Administração: um estudo em Apucarana-PR }\end{array}$ & 2014 \\
\hline \multicolumn{2}{|c|}{ Fonte: elaborato } \\
\hline
\end{tabular}

Fonte: elaborado pelos autores

Quadro 4 - Publicações no período 2014-2020

\begin{tabular}{|c|c|c|}
\hline Participante & Título & $\begin{array}{c}\text { Publicação } \\
\text { (ano) }\end{array}$ \\
\hline \multirow{4}{*}{$\begin{array}{c}\text { Amália Borges } \\
\text { Dário }\end{array}$} & $\begin{array}{c}\text { Avaliação de cotistas e não cotistas: uma } \\
\text { análise do desempenho acadêmico e da } \\
\text { evasão em um curso de Graduação em } \\
\text { Administração }\end{array}$ & $\begin{array}{c}\text { Capilo } \\
(2019), \\
\text { Evento } \\
(2017)\end{array}$ \\
\cline { 2 - 3 } & $\begin{array}{c}\text { Desempenho acadêmico e evasão: um } \\
\text { comparativo entre discentes cotistas e não } \\
\text { cotistas em um curso de Administração. }\end{array}$ & $\begin{array}{c}\text { Evento } \\
(2017)\end{array}$ \\
\hline \multirow{4}{*}{$\begin{array}{c}\text { Ana Paula } \\
\text { Guimarães }\end{array}$} & $\begin{array}{c}\text { Os parâmetros de avaliação do SINAES na } \\
\text { percepção dos estudantes do Curso de } \\
\text { Graduação em Administração }\end{array}$ & $\begin{array}{c}\text { Capítulo } \\
(2018)\end{array}$ \\
\cline { 2 - 3 } & $\begin{array}{c}\text { Gestão por competências: uma avaliação do } \\
\text { processo de recrutamento e seleção de } \\
\text { trabalhadores terceirizados }\end{array}$ & $\begin{array}{c}\text { Evento } \\
(2016)\end{array}$ \\
\cline { 2 - 3 } & $\begin{array}{c}\text { Gestão em educação superior a distância e o o } \\
\text { mundo do trabalho }\end{array}$ & $\begin{array}{c}\text { Evento } \\
(2014)\end{array}$ \\
\cline { 2 - 3 } & $\begin{array}{c}\text { Trabalho interdisciplinar: uma proposta de } \\
\text { inovação para o curso de administração da } \\
\text { faculdade de Apucarana. }\end{array}$ & $\begin{array}{c}\text { Evento } \\
(2014)\end{array}$ \\
\cline { 2 - 3 } & Avaliação de desempenho sob a ótica dos & Evento \\
& professores do Curso de Administração. & $(2014)$ \\
\cline { 2 - 3 } & Avaliação institucional: instrumentos de & Evento \\
\hline
\end{tabular}




\begin{tabular}{|c|c|c|}
\hline & $\begin{array}{l}\text { análise e suporte para qualidade do ensino } \\
\text { superior. }\end{array}$ & $(2014)$ \\
\hline $\begin{array}{l}\text { Carla Cristina } \\
\text { da Silveira } \\
\text { Trilha }\end{array}$ & $\begin{array}{c}\text { Almoxarifados de universidades públicas: } \\
\text { uma discussão sobre a avaliação de suas } \\
\text { atividades. In: }\end{array}$ & $\begin{array}{l}\text { Evento } \\
(2017)\end{array}$ \\
\hline $\begin{array}{l}\frac{\text { Carla Cristina }}{\frac{\text { da Silveira }}{\text { Trilha, }}} \\
\frac{\text { Guilherme K. }}{\text { Alves }}\end{array}$ & $\begin{array}{c}\text { Avaliação dos processos de compra com } \\
\text { dispensa de licitação: estudo em uma } \\
\text { universidade federal. }\end{array}$ & $\begin{array}{c}\text { Revista } \\
\text { (2018 e } \\
2019), \\
\text { Evento } \\
(2017) \\
\end{array}$ \\
\hline $\begin{array}{l}\text { Felipe Cintra } \\
\text { Nunes Braga } \\
\end{array}$ & $\begin{array}{l}\frac{\text { Divulgação de informações dos cursos }}{\text { superiores na internet: análise comparativa }} \\
\frac{\text { entre instituições federais de educação }}{\text { superior de Santa Catarina }}\end{array}$ & $\begin{array}{l}\text { Evento } \\
\text { (2020) }\end{array}$ \\
\hline \multirow{2}{*}{$\begin{array}{l}\text { Filipe José } \\
\text { Dias }\end{array}$} & $\begin{array}{l}\text { A internacionalização das universidades } \\
\text { federais do sul do Brasil. }\end{array}$ & $\begin{array}{l}\text { Evento } \\
(2017)\end{array}$ \\
\hline & $\begin{array}{l}\text { Acompanhamento de egressos de cursos de } \\
\text { graduação. }\end{array}$ & $\begin{array}{l}\text { Evento } \\
(2017)\end{array}$ \\
\hline \multirow[b]{2}{*}{$\begin{array}{l}\text { Guilherme } \\
\text { Krause Alves }\end{array}$} & $\begin{array}{c}\text { Avaliação da gestão dos processos de } \\
\text { compras: um comparativo entre universidades } \\
\text { públicas catarinenses }\end{array}$ & $\begin{array}{l}\text { Evento } \\
\text { (2017) }\end{array}$ \\
\hline & $\begin{array}{c}\text { Avaliação da internacionalização da educação } \\
\text { superior: indicadores e mapeamento de } \\
\text { processos. }\end{array}$ & $\begin{array}{l}\text { Capítulo } \\
\text { (2019), } \\
\text { Evento } \\
\text { (2017) }\end{array}$ \\
\hline $\begin{array}{l}\text { Joice Regina } \\
\text { da Costa S. da } \\
\text { Lapa }\end{array}$ & $\begin{array}{c}\text { Avaliação do contrato dos serviços de limpeza } \\
\text { e a gestão de terceirizados em uma } \\
\text { universidade federal }\end{array}$ & $\begin{array}{l}\text { Capítulo } \\
\text { (2019), } \\
\text { Evento } \\
\text { (2016) }\end{array}$ \\
\hline $\begin{array}{l}\text { Luiz Gustavo } \\
\text { Silva dos } \\
\text { Santos } \\
\end{array}$ & $\begin{array}{l}\frac{\text { Manutenção corretiva: uma avaliação da }}{\text { demanda de solicitações em uma instituição }} \\
\text { pública de educação superior }\end{array}$ & $\begin{array}{l}\text { Evento } \\
(2020)\end{array}$ \\
\hline $\begin{array}{l}\text { Renata } \\
\text { Silvério }\end{array}$ & $\begin{array}{l}\text { Cultura na universidade: o Projeto 12:30 da } \\
\text { Universidade Federal de Santa Catarina. }\end{array}$ & $\begin{array}{l}\text { Evento } \\
(2015)\end{array}$ \\
\hline \multirow{2}{*}{$\frac{\text { Ricardo João }}{\underline{\text { Magro }}}$} & $\begin{array}{l}\frac{\text { Avaliação da implantação do sistema de }}{\text { gestão administrativa na Universidade }} \\
\text { Federal de Santa Catarina segundo a } \\
\text { administração central da instituição. }\end{array}$ & $\begin{array}{l}\text { Evento } \\
(2020)\end{array}$ \\
\hline & $\begin{array}{l}\text { O sistema de gestão administrativa na } \\
\text { Universidade Federal de Santa Catarina: } \\
\text { aquisição e etapas iniciais de utilização. }\end{array}$ & $\begin{array}{l}\text { Evento } \\
(2020)\end{array}$ \\
\hline $\begin{array}{l}\text { Rosângela } \\
\text { Alves }\end{array}$ & $\begin{array}{l}\text { As diretrizes curriculares nacionais e os eixos } \\
\text { de formação da graduação em Direito: um } \\
\text { estudo nos docentes da UFSC }\end{array}$ & $\begin{array}{l}\text { Evento } \\
(2018)\end{array}$ \\
\hline \multirow[t]{2}{*}{$\begin{array}{l}\text { Sabrina } \\
\text { Fonseca de } \\
\text { Conto }\end{array}$} & $\begin{array}{c}\text { Crescimento dos Mestrados Profissionais na } \\
\text { Universidade Federal de Santa Catarina }\end{array}$ & $\begin{array}{l}\text { Revista } \\
\text { (2018), } \\
\text { Evento } \\
\text { (2017) }\end{array}$ \\
\hline & O documento de área da CAPES e o impacto & Evento \\
\hline
\end{tabular}




\begin{tabular}{|c|c|c|}
\hline & $\begin{array}{c}\text { na gestão de cursos de pós-graduação 'stricto } \\
\text { sensu': um estudo na Área de Comunicação e } \\
\text { Informação }\end{array}$ & (2017) \\
\hline $\begin{array}{c}\text { Tânia Regina } \\
\text { Tavares } \\
\text { Fernandes }\end{array}$ & $\begin{array}{c}\text { Gestão de processos em coordenadorias de } \\
\text { apoio administrativo: um estudo de caso nos } \\
\text { centros de ensino de uma universidade } \\
\text { pública. }\end{array}$ & $\begin{array}{c}\text { Evento } \\
(2018)\end{array}$ \\
\hline $\begin{array}{c}\text { Tânia Regina } \\
\text { Tavares } \\
\begin{array}{c}\text { Fernandes; } \\
\text { Maria das } \\
\text { Graças } \\
\text { Martins }\end{array}\end{array} \begin{array}{c}\text { Coordenadoria de Apoio Administrativo do } \\
\text { Centro de Ciências da Saúde de uma } \\
\text { universidade pública. }\end{array}$ & $\begin{array}{c}\text { Evento } \\
\text { (2015) }\end{array}$ \\
\hline
\end{tabular}

Fonte: elaborado pelos autores

\section{CONSIDERAÇÕES FINAIS}

A avaliação representa uma contribuição relevante nos processos de gestão. A noção de que a gestão possui um ciclo que inclui planejamento, formulação e implantação de estratégias, projetos ou programas requer que tal ciclo inclua a avaliação contínua, periódica ou programada para que seja possível verificar se as intenções apresentadas no planejamento e conduzidas na implantação de projetos, estratégias ou políticas ocorreram de acordo com o esperado.

Nos ambientes educacionais, a avaliação institucional representa um papel significativo, principalmente por se tratar de, necessariamente, de implicar em uma condução multidisciplinar, envolvendo pessoas de diferentes formações.

No entanto, um programa de pós-graduação na área de Administração precisa ter projetos que envolvam conhecimentos específicos desta área de conhecimento. O Programa de Pós-Graduação em Administração Universitária da Universidade Federal de Santa Catarina (PPGAU) possui linha de pesquisa direcionada para a avaliação da educação superior e projetos de pesquisa específicos desde a criação do programa em 2010.

Este trabalho fez um corte, identificando a produção no período 2014-2020, onde forma identificados:

- Oito (8) dissertações concluídas;

- Quatro (4) publicações em revistas acadêmicas;

- Quatro (4) capítulos de livros publicados;

- Vinte e três (23) publicações em eventos. 
Cabe destacar, por fim, que a produção do programa é maior do que está aqui apresentado. A delimitação definida é a de um projeto de avaliação criado em 2014, renovado em 2016 e 2018 e existem outras produções que ocorreram na mesma linha de pesquisa neste período. Uma necessária expansão da coleta contribuiria para estabelecer um quadro completo sobre a gestão das instituições de educação superior. 


\section{REFERÊNCIAS}

Afonso, a.j. Avaliação educacional: regulação e emancipação para uma sociologia das políticas avaliativas contemporâneas. São paulo: cortez, 2000.

Allen, n. L. Avaliação em larga escala: lições de experiências. In: anais. Sociedade brasileira para o progresso da ciência, 1996.

Arantes, n. Sistemas de gestão empresarial. São paulo: atlas, 1998.

Atkinson, a. Strategic performance measurement and incentive compensation. European management journal, v. 16, oct. 2000.

Buchele, r. B. Políticas administrativas para empresas em crescimento (manual para avaliação). São paulo: atlas, 1971.

Corrêa, h. L. O estado da arte da avaliação de empresas estatais. Universidade de são paulo, são paulo, tese de doutoramento, 1986.

Correa, a. C.; erdmann, r.h.; melo, p.a.; rissi, m.; tecchio, e.l. Mapa estratégico para as ies fundamentado em um sistema de gestão integrado: uma proposta metodológica para a implementação do pdi. In: viii colóquio internacional sobre gestión universitaria em america del sur. Assunción, paraguay. Anais... Universidad tecnologica intercontinental, p.1-16, 2008.

Debusk, g.k, brown, r.m.; killough, I.n. Components and relative weights in utilization of dashboard systems like the balanced scorecard. The british accounting review, 35, 2003.

Durhan, eunice r. Avaliação e relações com o setor produtivo: novas técnicas do ensino europeu. São paulo: usp/nupes, 1990.

Drucker, p. F. Prática de administração de empresas. Rio de janeiro: fundação de cultura. 1968

Edvinsson, leif; malone, m. S. Capital intelectual. São paulo: makron books. 1998.

Farias netto, p. S. Gestão efetiva e privatização. Rio de janeiro: qualitimark, 1994.

Greenwood, r. G. Management by objectives: as developed by peter drucker, assisted by harold smiddy. Academy of management. The academy of management review. Pp. 225-230. Apr 1981. 
Hourneaux jr., f. Avaliação de desempenho organizacional: estudo de casos de empresas do setor químico. Universidade de são paulo, são paulo, dissertação de mestrado, 2005.

Hourneaux jr., f.; correa, I.a.; maximiano, a.c.a. A contribuição dos prêmios de qualidade para a gestão do desempenho na empresa. Ix semead seminários em administração fea usp, são paulo, 2006.

House, e. R. Tendencias em evaluación. Educación, madrid, n.299, p. 43-55, 1992.

Kaplan, r.s, norton, d.p. A estratégia em ação - balanced scorecard. Rio de janeiro: campus, 1997.

Kaplan, r.s, norton, d.p. Leading change with the balanced scorecard. Financial executive, sep 2001.

Kaplan, r.s, norton, d.p. Organização orientada para a estratégia: como as empresas que adotam o balanced scorecard prosperam no novo ambiente de negócios. 2. Ed. Rio de janeiro: campus, 2000.

Kaplan, r.s, norton, d.p. Strategic learning \& the balanced scorecard. Strategy \& leadership. Sep/oct 1996.

Lodi, j. B. Administração por objetivos. São paulo: pioneira. 1976.

Lupoli jr., j. G. Ângelo, c. F. De. A importância dos objetivos na implementação de modelos de gestão. Caderno de pesquisas em administração, são paulo, v. 09, no 2, abril/junho. 2002.

Marcelino, g.; matias-pereira, j.; berbert, c.o. Gestão estratégica em ciência e tecnologia: avaliação de uma experiência de alinhamento estratégico no governo federal. In: mendonça, g.m. Estudos contemporâneos em organização e gestão. São luis: uema, p.111-148, 2008.

Martindell, j. The scientific appraisal of management. New york: harper \& brothers, 1950.

Olve, n.g.; roy, j.; wetter, m. Condutores de performance: um guia prático para o uso do "balanced scorecard". Rio de janeiro: qualitymark, 2001.

Pnq. Modelo de excelência do pnq. 2007. Disponível em <www.fnq.org.br > acesso em 12/06/2017. 
Rezende, j. F. Balanced scorecard e a gestão do capital intelectual. Rio de janeiro:campus, 2003

Robbins, s. P. O processo administrativo: integrando teoria e prática. São paulo: atlas, 1978.

Rodrigues, c.m.c. Proposta de avaliação integrada ao planejamento anual: um modelo para ucg. Tese de doutorado da universidade federal do rio grande do sul. Porto alegre, 2003.

Rosa jr, a.x. Modelo de tableau de bord de gestion para empresas brasileiras com base na contabilidade em atividades. Dissertação de mestrado em engenharia de produção ufsc, florianópolis, 2003.

Schlickman, r.; melo, p. A. De. Administração universitária: em busca de uma epistemologia. Avaliação, campinas, v.17, n.1, p.155-178, mar.2012.

Schwartzman, e.r. A institucionalização da avaliação. In: durhan, eunice r.; schwartzman, s. (org.). Avaliação do ensino superior. São paulo: edusp, 1992.

Schwartzman, s. O contexto institucional e político da avaliação do ensino superior. Núcleo de pesquisa sobre ensino superior universidade de são paulo. São paulo: usp, 1990.

The sigma project, 2003, the sigma guidelines-putting sustainable development into pratice- a guide for organizations. London, uk: bsi.

Warrack, b. J.; sinha, m. N.; bawden, g. A performance measurement framework for inspection effectiveness at system level. Annual quality congress proceedings, 2001. 